\title{
Afterload excess and myocardial performance
}

\author{
Meghana Jayam*, Danielle Janosevic, Madhavi Kadiyala, Jie J Cao, Simcha Pollack, Nathaniel Reichek \\ From 16th Annual SCMR Scientific Sessions \\ San Francisco, CA, USA. 31 January - 3 February 2013
}

\section{Background}

Systolic circumferential and longitudinal strain(CSt\%, LSt $\%)$ are widely used to assess myocardial performance, but their afterload dependence has not been well characterized. Using geometric estimates of left ventricular (LV) circumferential and meridional wall stress(CWS, MWS) as indices of afterload at the myocardial level, we compared LV CSt and LSt to estimates of CWS and MWS in normals (NL, $\mathrm{n}=39,46 \%$ female, age $54.6+/-14.6 \mathrm{yrs}$ ) and patients with dilated cardiomyopathy (DCM, $\mathrm{n}=35,23 \%$ female, age $50.8+/-15.0 \mathrm{yrs}$, EF $27.2+/-10.8 \%$ ).

\section{Methods}

Breath-hold retrospectively gated SSFP cine images in short and long axis planes and cuff systolic blood pressure $(\mathrm{P})$ during imaging were obtained and mid LV and "global" (average of basal, midLV and apical) CSt\% and LSt\% determined using feature tracking (2D CPA MR, TomTec Imaging Systems, Munich). Mid-LV CWS and MWS were estimated using Mirsky's published formulae $(C W S=P(B / h)[1-(B 2 / 2 A 2)-(h / 2 b)$; where $h=e n d-$ systolic(ES) $\mathrm{LV}$ wall thickness, $\mathrm{A}=\mathrm{ES}$ midwall semimajor axis $([\mathrm{L}+\mathrm{h}] / 2), \mathrm{B}=\mathrm{ES}$ midwall semiminor axis $([\mathrm{D}+\mathrm{h}] / 2))$ and $M W S=P R i /(2 h(1+h / 2 R i)$ where $\mathrm{Ri}=$ short axis $\mathrm{LV}$ radius).

\section{Results}

Mean mid-LV CSt\% was $-22.2+/-4.8 \%$ in NL but markedly reduced in DCM $(-9.3+/-5.0 \%, \mathrm{p}<0.0001)$ while mean mid-LV LSt $\%$ was $-14.7 /-+8.9$ in NL and markedly reduced in $\mathrm{DCM}(-8.6+/-4.6, \mathrm{p}<0.0006)$. Reductions in $\mathrm{CSt} \%$ and LSt\% in DCM were associated with markedly elevated CWS (307.6+/-9.2 vs $176.2+/-42.1 \times 103 \mathrm{dyn} / \mathrm{cm} 2$ in NL, $\mathrm{p}<0.0001)$ and MWS(195.6+/-69.6 vs. $92.0+/-25.7$ $\mathrm{x} 103 \mathrm{dyn} / \mathrm{cm} 2, \mathrm{p}<0.001)$. Similar results were obtained for "global" CSt\% and LSt\%, the means of CSt\% and LSt $\%$ at basal, mid-LV and apical slice locations(Table 1) and for MWS versus LV long axis shortening. The relationship between CWS and mid-LV CSt\% was CSt\% = 0.055CWS-29.3, $\mathrm{r}=-0.64, \mathrm{p}<0.001$. Therefore, if NL LV myocardium were exposed to the same afterload(CWS) as in DCM, mean CST\% might fall from $-22.3 \%$ to $-12.1 \%$. Similar effects would be seen on LSt\% under the markedly increased MWS found in DCM. Thus, afterload excess due to adverse remodeling and noncompensatory(inadequate) hypertrophy could account for as much as $79 \%$ of the reduction in strain in DCM, and altered myocyte "contractile state" and altered myocardial composition for as little as $21 \%$ of the deficit.

\section{Conclusions}

We conclude that afterload excess is a major contributor to impaired systolic function in DCM and normalization of contractile state and myocardial composition alone may not restore normal function. Consideration of effects of afterload excess, inadequate hypertrophy and adverse remodeling on myocardial strain is essential in the evaluation of pathophysiology.

\section{Funding}

This study was supported by the St. Francis Research Foundation.

Table 1 Global Circumferential and Longitudinal Strains and Wall Stress

\begin{tabular}{|c|c|c|c|}
\hline & Normal $n=39$ & $\mathrm{DCM} n=35$ & t-test \\
\hline Variable & mean(s.d.) & mean(s.d.) & $p$-value \\
\hline Global Circ Strain(\%) & $-23.8(4.3)$ & $-10.7(5.3)$ & $<0.0001$ \\
\hline Circ Wall Stress $\times 10^{3}$ dynes $/ \mathrm{cm} 2$ & $176.2(42.1)$ & $307.6(89.2)$ & $<0.0001$ \\
\hline Global Long. Strain(\%) & $-16.2(4.5)$ & $-8.6(4)$ & $<0.0001$ \\
\hline Meridional Stress $\times 10^{3}$ dynes $/ \mathrm{cm} 2$ & $92.0(25.7)$ & 195.6(69.6) & $<0.0001$ \\
\hline
\end{tabular}

Research, St. Francis Hospital, Roslyn, NY, USA

(c) 2013 Jayam et al; licensee BioMed Central Ltd. This is an Open Access article distributed under the terms of the Creative Commons 
- Convenient online submission

- Thorough peer review

- No space constraints or color figure charges

- Immediate publication on acceptance

- Inclusion in PubMed, CAS, Scopus and Google Scholar

- Research which is freely available for redistribution 